Original Article

\title{
Morin alleviates fructose-induced metabolic syndrome in rats via ameliorating oxidative stress, inflammatory and fibrotic markers
}

\author{
Gehan Hussein Heeba ${ }^{1}$, Esraa Mohamed Rabie ${ }^{1}$, Mekky Mohamed Abuzeid ${ }^{2}$, Amany Abdelrehim Bekhit ${ }^{2 *}$, and \\ Mohamed Montaser Khalifa ${ }^{1}$
}

'Departments of Pharmacology and Toxicology, and '2Biochemistry, Faculty of Pharmacy, Minia University, El-Minia 61111, Egypt

\section{ARTICLE INFO \\ Received March 10, 2020 \\ Revised August 26, 2020 \\ Accepted September 10, 2020 \\ *Correspondence \\ Amany Abdelrehim Bekhit \\ E-mail: umkareem05@yahoo.com}

Key Words

Flavonoids

Fructose

Insulin resistance

Liver

Metabolic syndrome

\begin{abstract}
Metabolic syndrome (MBS) is a widespread disease that has strongly related to unhealthy diet and low physical activity, which initiate more serious conditions such as obesity, cardiovascular diseases and type 2 diabetes mellitus. This study aimed to examine the therapeutic effects of morin, as one of the flavonoids constituents, which widely exists in many herbs and fruits, against some metabolic and hepatic manifestations observed in MBS rats and the feasible related mechanisms. MBS was induced in rats by high fructose diet feeding for 12 weeks. Morin $(30 \mathrm{mg} /$ $\mathrm{kg}$ ) was administered orally to both normal and MBS rats for 4 weeks. Liver tissues were used for determination of liver index, hepatic expression of glucose transporter 2 (GLUT2) as well as both inflammatory and fibrotic markers. The fat/muscle ratio, metabolic parameters, systolic blood pressure, and oxidative stress markers were also determined. Our data confirmed that the administration of morin in fructose diet rats significantly reduced the elevated systolic blood pressure. The altered levels of metabolic parameters such as blood glucose, serum insulin, serum lipid profile, and oxidative stress markers were also reversed approximately to the normal values. In addition, morin treatment decreased liver index, serum liver enzyme activities, and fat/muscle ratio. Furthermore, morin relatively up-regulated GLUT2 expression, however, down-regulated NF- $\mathrm{KB}$, TNF- $\alpha$, and TGF- $\beta$ expressions in the hepatic tissues. Here, we revealed that morin has an exquisite effect against metabolic disorders in the experimental model through, at least in part, antioxidant, anti-inflammatory, and anti-fibrotic mechanisms.
\end{abstract}

\section{INTRODUCTION}

The over consumption of unbalanced diet is considered one of the major health problems in the modern societies, leading to a high prevalence of metabolic syndrome (MBS) associated with immoderate abdominal obesity, insulin resistance, hypertension and dyslipidemia [1-3]. These components of MBS participate in excessive reactive oxygen species (ROS) generation and impairment of antioxidant defense mechanisms in our bodies. Eventually, these conditions certainly increase the incidence of MBS pathogenesis [4], like type 2 diabetes mellitus (T2DM) and cardiovascular morbidities [5].

Plant flavonoids can restore metabolic disorders related to the development of some diseases such as obesity and T2DM [6] via their antioxidant, anti-inflammatory, cardioprotective and anticancer activities [7-9]. Thus, recently, bioactive compounds from dietary plants and fruits have been gaining a growing interest to encounter many fatal consequences of chronic diseases without noticeable side effects. For example, apigenin is one of the active ingredients in Chinese medicinal herbs caused apoptosis in (c) (i) (\$) This is an Open Access article distributed under the terms of the Creative Commons Attribution Non-Commercial License, which permits unrestricted non-commercial use, distribution, and reproduction in any medium, provided the original work is properly cited. Copyright $\odot$ Korean J Physiol Pharmacol, pISSN 1226-4512, elSSN 2093-3827
Author contributions: G.H.H. designed the study, E.M.R. performed the experiments and did the statistical analysis, M.M.A. and M.M.K. assisted with methodology and contributed resources. A.A.B. wrote the first draft of the manuscript, and all authors contributed to the editing of the revised manuscript, and approved the manuscript. 
prostatic cancer by alternating the $\mathrm{Bax} / \mathrm{Bcl}-2$ ratio in favor of cell apoptosis [10]. Also, polyphenols such as quercetin are widely distributed in plant could regulate blood pressure by activating $\mathrm{Na}^{+}-\mathrm{K}^{+}-2 \mathrm{Cl}^{-}$cotransporter 1 (NKCCl), leading to elevation of the cytosolic $\mathrm{Cl}^{-}$concentration $\left(\left[\mathrm{Cl}^{-}\right]_{\mathrm{c}}\right)$ which down-regulates gene expression of epithelial $\mathrm{Na}^{+}$channels (ENaC) [11].

Morin ( $2^{\prime}, 3,4^{\prime}, 5,7$-pentahydroxyflavone) is a C15 flavonoid structure, containing three phenolic rings, which was first isolated in the year 1830 [12]. Morin is a yellowish pigment, exists in a mill, fig, guava leaves, onion, apple and other Moraceae, which has been used in folk medicine [13]. In earlier studies, the low cytotoxicity of morin has been reported on cellular cultures and animal models and treatment with morin orally at chronic doses did not exhibit any toxicity [14]. Tests in vivo have emphasized that the plasma concentration of morin does notexceed $1 \%$ after oral administration of high doses $(200 \mathrm{mg} / \mathrm{kg})$ Since it has low bioavailability and well tolerated natural antioxidant [15].

Moreover, it was indicated that morin possesses protective properties of many human cell types [16] such as antioxidant, anti-inflammatory, antinociceptive, antihyperglycemic, and antiangiogenic effects [17].

We previously provided strong evidence for the hepatoprotective and anti-fibrotic activities of morin by attenuating the expression of NF- $\kappa B$ and pro-inflammatory cytokines [18]. In this study, we confirm that the administration of morin could recover the clinical and biochemical features of MBS complications. Thus, our current study was aimed to examine the possible beneficial effects of morin in fructose induced metabolic syndromes in an experimental model and to indicate the underlying its mechanisms.

\section{METHODS}

\section{Drugs and chemicals}

Morin was purchased from Sigma-Aldrich Chemical Co. (St Louis, MO, USA). Fructose powder was purchased from Safety Masr, Cairo, Egypt. Polyclonal rabbit/anti-rat antibodies against tumor necrosis factor- $\alpha$ (TNF- $\alpha$ ) and transforming growth factor- $\beta$ (TGF- $\beta$ ) were purchased from Santa Cruz Biotechnology Inc. (Dallas, TX, USA). All other chemicals and solvents were of the highest grade commercially available. Morin was freshly prepared in a $0.5 \%$ aqueous solution of carboxymethyl cellulose.

\section{Animals and experimental design}

The study was conducted in accordance with the Basic \& Clinical Pharmacology \& Toxicology (BCPT) policy for experimental and clinical studies [19]. Adult male Wistar rats (8 weeks of age) weighing 180-200 g were obtained from the animal house, Faculty of Agriculture, Minia University. Rats were housed in stainless steel cages with free access to water and standard laboratory food (El-Nasr Company, Abou-Zaabal, Cairo, Egypt), and left to acclimatize for a week before the study under controlled laboratory conditions of normal light/dark cycle and temperature. The study protocol was approved by the Pharmacology and Toxicology Department, Faculty of Pharmacy, Minia University, Egypt 44/2019.

The animals cared according to the principles and guidelines of the Canadian Council on Animal Care (Vol. 1, 2nd ed., 1993, and Vol. 2, 1984 available from the Canadian Council on Animal Care, Constitution Square, Tower 2, Suite 315, 350 Albert Street, Ottawa, ON K1R1B1, Canada, or on their Web site at www.ccac.ca).

Rats were randomly assigned in four groups of eight animals each. The first group was fed standard chow diet and served as a control group. Animals in the second group were fed a normal diet throughout the study and received morin $(30 \mathrm{mg} / \mathrm{kg} /$ day, orally) in the last four weeks, and served as a control morin group.

Animals in the third and fourth groups were fed high fructose diet, then started administration of morin in for four weeks as first and second groups. For the fructose diet, we used an adapted diet standardized by Botezelli et al. [20] composed of $60 \%$ fructose $(\mathrm{W} / \mathrm{W})$ in diet for 12 weeks. The control group received the vehicle ( $0.5 \%$ aqueous solution of carboxymethyl cellulose). The last group was given morin (30 mg/kg/day, orally) [21].

\section{Measurement of blood pressure by non-invasive method}

Systolic blood pressure (SBP) was determined at the start of the study and every 2 weeks during the induction of MBS and then, weekly during morin treatment by a tail-cuff method with an automatic sphygmomanometer (LE 5001 Pressure METERS; PanLab Harvard Apparatus, Barcelona, Spain).

\section{Blood and tissue samples}

Rats were exposed to light anesthesia by diethyl ether and blood samples were collected from retro-orbital sinus veins via glass capillaries before ( 0 time) and at $30,60,90$, and $120 \mathrm{~min}$ after oral glucose loading $(2 \mathrm{~g} / \mathrm{kg})$. Glucose concentration was determined with an automatic blood glucose meter (Super Glucocard, Kyoto, Japan) for the determination of oral glucose tolerance test (OGTT).

On the second day, rats were weighed, and then overnight fasted rats were sacrificed, then blood samples were collected from neck vessels by decapitation. Clear sera were separated and kept at $-80^{\circ} \mathrm{C}$ until an assessment of various parameters. The liver was rapidly dissected out, blotted dry, weighed, and then the liver index was calculated according to the formula: (weight/body weight) $\times 100$. Liver tissues were divided into two parts. The first part was put in $10 \%$ formalin for histopathology examination, while the second part was kept at $-80^{\circ} \mathrm{C}$ for biochemical analysis. 
The visceral fat pads and the gastrocnemius muscles were excised, blotted dry and weighed and the ratio of visceral fat to the gastrocnemius muscle $(\mathrm{g} / \mathrm{g})$ was considered as an index of body/ muscle ratio [22].

\section{Biochemical measurements}

Serum alanine aminotransferase (ALT) and aspartate aminotransferase (AST) activities were determined by using available commercial kits (Bio-diagnostic, Cairo, Egypt). Fasting blood glucose level was measured using an automatic blood glucose meter (Super Glucocard) and fasting serum insulin was determined using ultrasensitive rat insulin ELISA kit (Bio-Source, Europe S.A., Nivelles, Belgium). Insulin resistance was determined using the homeostasis model assessment index for insulin resistance (HOMA-IR) utilizing the following formula: HOMA-IR index = [fasting glucose $(\mathrm{mg} / \mathrm{dl}) \times$ fasting insulin $(\mu \mathrm{U} / \mathrm{ml}) / 405$ ] according to Matthews et al. [23]. Serum total cholesterol (TC), high-density lipoprotein cholesterol (HDL-C) and triglycerides (TG) were determined using commercially available colorimetric kits (Biodiagnostic, Cairo, Egypt). Serum level of low density lipoprotein cholesterol (LDL-C) was calculated using the formula that was reported by Friedewald et al. [24].

\section{Assessment of hepatic oxidative stress parameters}

Hepatic lipid peroxidation was determined as malondialdehyde (MDA) by the reaction with thiobarbituric acid according to the method of Ohkawa et al. [25]. Nitric oxide (NO) level was measured as total nitrite/nitrate that is the end degradation products of NO through the reduction of nitrate into nitrite using coppered cadmium, followed by color development with the Griess reagent in acidic medium [26]. Reduced glutathione (GSH) was determined according to the method described by Beutler et al. [27]. Catalase (CAT) activity was determined by commercially available kits according to the manufacturer's guidelines (Biodiagnostic).

\section{Reverse transcription polymerase chain reaction (RT- PCR)}

Total RNA was extracted from liver samples using the RNA extraction kit according to the manufacturer's instructions (Qiagen, Tokyo, Japan). RNA (5 $\mu \mathrm{g})$ was then transcribed using Revert Aid First Strand cDNA Synthesis kit (Ferments Life Science, Fort Collins, CO, USA). The cDNA products were amplified by PCR in a total volume of $50 \mu \mathrm{l}$ containing $2.5 \mathrm{U}$ Taq DNA polymerase plus 10 pmol of the upstream and downstream primers for nuclear factor kappa- $\beta$ (NF- $\mathrm{KB}$ ) (Forward: 5'-GTCATCAGGAAGAGGTTTGGCT-3'; Reverse: 5'-TGATAAGCTTAGCCCTTGCAGC-3'), glucose transporter-2 (GLUT2) (Forward: 5'-GGAAATAGAAAGTTGACTGGCCC-3'; Reverse:
5'-TGATAAGCTTAGCCCTTGCAGC-3'). As an internal control, we also estimated the expression of $\beta$-actin mRNA using the sequences of the following primers: Forward: 5'-TCACCCTGAAGTACCCCATGG AG-3'; Reverse: 5'-TTGGCCTTGGGG TTCAGGGGG-3'. Amplified products $(5 \mu \mathrm{l})$ were loaded into $1.5 \%$ agarose gels previously stained with $0.5 \mu \mathrm{g} / \mathrm{ml}$ ethidium bromide, electrophoresed at $100 \mathrm{~V}$ for $30 \mathrm{~min}$ and then examined under a UVP gel imaging system (UVP Co., Upland, CA, USA). Images were analyzed with the Gel-Pro Analyzer Version 3.0, and the semi-quantitative measure of mRNA expression was expressed as the ratio of the optical density (OD) of NF- $\kappa \mathrm{B}$ or GLUT2 to that of $\beta$-actin.

\section{Western blot analysis}

TNF- $\alpha$ and TGF- $\beta$ protein expressions in the liver tissues were determined by the Western blot method. Liver tissue samples were homogenized in lysis buffer $(20 \mathrm{mM}$ Tris- $\mathrm{HCl} \mathrm{pH} \mathrm{7.5,} 50$ mM 2-mercaptoethanol, 5 mM EGTA, 2 mM EDTA, 1\% NP40, $0.1 \%$ SDS, $0.5 \%$ deoxycholic acid, $10 \mathrm{mM} \mathrm{NaF}, 1 \mathrm{mM}$ PMSF, 25 $\mathrm{mg} / \mathrm{ml}$ leupeptin, $2 \mathrm{mg} / \mathrm{ml}$ aprotinin), then protein concentrations were determined. For direct immune-blotting, aliquots of lysate were mixed with loading buffer containing 2-mercaptoethanol and then kept at $100^{\circ} \mathrm{C}$ for 10 min before loading on $10 \%$ SDS-PAGE. Following SDS-PAGE separation, proteins were transferred to PVDF membrane. Membranes were blocked in TBST containing 5\% (w/v) non-fat milk and dried for $1 \mathrm{~h}$ at room temperature. Membrane strips were incubated with primary antibodies (1:1,000 for TNF- $\alpha$, TGF- $\beta$, and $\beta$-actin) overnight at $4^{\circ} \mathrm{C}$. Following extensive washing, membrane strips were incubated with anti-rabbit IgG (1:5,000; Cell Signaling Technology Inc., Beverly, MA, USA) conjugated to horseradish peroxidase for $1 \mathrm{~h}$. Protein bands were detected by a standard enhanced chemiluminescence method and densitometry measurements were made using Image J software (freeware; rsbweb.nih.gov/ij).

\section{Histopathology examination}

Liver specimens were fixed in 10\% formalin and processed for paraffin sections of $4 \mu \mathrm{m}$ thickness. Sections were stained with hematoxylin and eosin for routine histopathological examination. All histological examinations were performed by an experienced pathologist who was blinded to the experimental groups.

\section{Statistical analysis}

Results were expressed as means \pm standard error of the mean (SEM) and were analyzed for statistically significant differences using one-way analysis of variance (ANOVA) followed by the Tukey-Kramer post-analysis test to compare all groups. For SBP, two-way ANOVA followed by Bonferroni post-analysis test was used. P-values less than 0.05 were considered significant. Graph- 
Pad Prism was used for statistical calculations (Version 5.00 for Windows; GraphPad Software, San Diego, CA, USA).

\section{RESULTS}

\section{Effect of morin on fat/muscle ratio, liver index and liver enzyme activities}

The results in Table 1 revealed a significant $(\mathrm{p}<0.05)$ elevation in the fat/muscle ratio, liver index and liver enzyme activities (ALT and AST) in the MBS group compared to the control group. On the other hand, the above-mentioned parameters were significantly $(\mathrm{p}<0.05)$ reduced after the treatment with morin when compared to non-treated MBS group. These results indicate that morin improves hepatic steatosis through reversing of liver enzyme levels. Typically the range for normal AST is reported between 10 to $40 \mathrm{U} / \mathrm{L}$ and ALT between 7 to $56 \mathrm{U} / \mathrm{L}$.

\section{Effect of morin on blood glucose level, serum insulin, insulin resistance, OGTT and lipid profile}

The administration of morin significant $(\mathrm{p}<0.05)$ reduced insulin resistance parameters to nearly control values (Table 2). Regarding OGTT, by feeding the fructose diet for 12 weeks in the MBS group the area under the curve (AUC) value was significantly raised as compared to the control group (Fig. 1).

Nevertheless, the AUC value in the group treated with morin was significantly declined as compared to the control group. As shown in Table 2, fructose diet induced a major disturbance in lipid profile in the MBS group as indicated via the significant ( $p$ $<0.05$ ) elevation in serum TC, TG, and LDL-C levels, while the serum HDL-C level showed a significant $(\mathrm{p}<0.05)$ reduction. These data suggested that oral administration of morin might attenuate the fructose diet-induced dyslipidemia in the MBS group (Table 2).

For the majority of healthy individuals, normal blood glucose levels (72-99 mg/dl when fasting) were increased up to $140 \mathrm{mg} / \mathrm{dl}$ $2 \mathrm{~h}$ after meal.

Fasting insulin was between 3-8 $\mu \mathrm{IU} / \mathrm{ml}$. Glucose/insulin as HOMA-IR is near 1 (0.5-1.5). TC was less than $200 \mathrm{mg} / \mathrm{dl}$. Fasting TG was less than $150 \mathrm{mg} / \mathrm{dl}$. HDL level was $60 \mathrm{mg} / \mathrm{dl}$ and LDL level was $100-129 \mathrm{mg} / \mathrm{dl}$.

\section{Effect of morin on hepatic oxidative stress markers}

In the MBS rats, hepatic levels of MDA and NO were significantly $(\mathrm{p}<0.05)$ increased. In the same line, the decrease in GSH level and catalase activity were significantly $(\mathrm{p}<0.05)$ observed as compared to the control group. The treatment with morin could reduce oxidative stress marker values significantly as compared to the control group $(\mathrm{p}<0.05)$.

The results elucidated that the antioxidant capacity of morin may be contributed to the protective effects against metabolic dysfunction (Table 3).

Table 1. Effect of morin on body/muscle ratio, liver index, serum ALT and serum AST in fructose-induced metabolic syndrome in rats

\begin{tabular}{lcccc}
\hline Groups & Body/muscle ratio $(\mathrm{g} / \mathrm{g})$ & Liver index $(\%)$ & ALT $(\mathrm{IU} / \mathrm{L})$ & AST $($ IUU/L) \\
\hline Control & $2.66 \pm 0.23$ & $2.72 \pm 0.22$ & $33.2 \pm 3.11$ & $64 \pm 3.20$ \\
MOR & $2.63 \pm 0.24$ & $2.41 \pm 0.11$ & $33.5 \pm 1.33$ & $60.6 \pm 5.03$ \\
MBS & $5.22 \pm 0.41^{\mathrm{a}}$ & $4.46 \pm 0.41^{\mathrm{a}}$ & $75.2 \pm 4.13^{\mathrm{a}}$ & $126 \pm 2.53^{\mathrm{a}}$ \\
MBS + MOR & $4.16 \pm 0.25^{\mathrm{a}, \mathrm{b}}$ & $3.15 \pm 0.16^{\mathrm{b}}$ & $53.3 \pm 2.48^{\mathrm{a}, \mathrm{b}}$ & $83.1 \pm 6.51^{\mathrm{a}, \mathrm{b}}$ \\
\hline
\end{tabular}

Data are represented as mean \pm SEM $(n=8$ rats). ALT, alanine aminotransferase; AST, aspartate aminotransferase; MBS, metabolic syndrome; MOR, morin. ${ }^{\mathrm{a}, \mathrm{b}}$ Significantly different from normal control and MBS groups, respectively at $\mathrm{p}<0.05$.

Table 2. Effect of morin on metabolic parameters in fructose-induced metabolic syndrome in rats

\begin{tabular}{lccccccc}
\hline \multicolumn{1}{c}{ Groups } & $\begin{array}{c}\text { Blood } \\
\text { glucose } \\
(\mathrm{mg} / \mathrm{dl})\end{array}$ & $\begin{array}{c}\text { Serum } \\
\text { insulin } \\
(\mu \mathrm{lU} / \mathrm{ml})\end{array}$ & $\begin{array}{c}\text { HOMA-IR } \\
\text { index }\end{array}$ & $\begin{array}{c}\text { TC } \\
(\mathrm{mg} / \mathrm{dl})\end{array}$ & $\begin{array}{c}\text { TG } \\
(\mathrm{mg} / \mathrm{dl})\end{array}$ & $\begin{array}{c}\text { HDL-C } \\
(\mathrm{mg} / \mathrm{dl})\end{array}$ & $\begin{array}{c}\text { LDL-C } \\
(\mathrm{mg} / \mathrm{dl})\end{array}$ \\
\hline Control & $94 \pm 5.3$ & $10.3 \pm 0.42$ & $2.3 \pm 0.16$ & $82 \pm 4.4$ & $103 \pm 3.4$ & $42 \pm 2.2$ & $23 \pm 2.4$ \\
MOR & $92 \pm 4.6$ & $11.1 \pm 0.80$ & $2.4 \pm 0.19$ & $81 \pm 3.5$ & $101 \pm 2.1$ & $48 \pm 1.5$ & $21 \pm 1.9$ \\
MBS & $162 \pm 6.2^{\mathrm{a}}$ & $17.0 \pm 0.64^{\mathrm{a}}$ & $6.8 \pm 0.48^{\mathrm{a}}$ & $152 \pm 5.1^{\mathrm{a}}$ & $215 \pm 8.2^{\mathrm{a}}$ & $24 \pm 1.4^{\mathrm{a}}$ & $85 \pm 3.7^{\mathrm{a}}$ \\
MBS + MOR & $134 \pm 2.8^{\mathrm{a}, \mathrm{b}}$ & $12.2 \pm 0.73^{\mathrm{a}, \mathrm{b}}$ & $4.7 \pm 0.34^{\mathrm{a}, \mathrm{b}}$ & $107 \pm 4.5^{\mathrm{a}, \mathrm{b}}$ & $161 \pm 7.9^{\mathrm{a}, \mathrm{b}}$ & $43 \pm 2.8^{\mathrm{b}}$ & $33 \pm 1.9^{\mathrm{b}}$ \\
\hline
\end{tabular}

Data are represented as mean \pm SEM ( $\mathrm{n}=8$ rats). MBS, metabolic syndrome; MOR, morin; TC, total cholesterol; TG, triglycerides; HDL-C, high density lipoprotein cholesterol; LDL-C, low density lipoprotein cholesterol. ${ }^{a, b}$ Significantly different from normal control and MBS groups, respectively at $\mathrm{p}<0.05$. Homeostasis Model Assessment-Insulin Resistance $(\mathrm{HOMA}-\mathrm{IR})=[$ fasting glucose $(\mathrm{mg} / \mathrm{dl}) \mathrm{x}$ fasting insulin $(\mu \mathrm{IU} / \mathrm{ml})] / 405$. 


\section{Effect of morin on systolic blood pressure (SBP) changes}

At the beginning of our experiment, the SBP value was similar in all groups (119-124 mmHg). Oral ingestion of fructose diet for 12 weeks elevated the SBP value significantly $(\mathrm{p}<0.05)$ in comparison to the control group. On the other hand, morin intake significantly $(\mathrm{p}<0.05)$ reduced the SBP value as compared to the MBS group (Fig. 2). Such a result assessed the antihypertensive effect of morin.

\section{A}

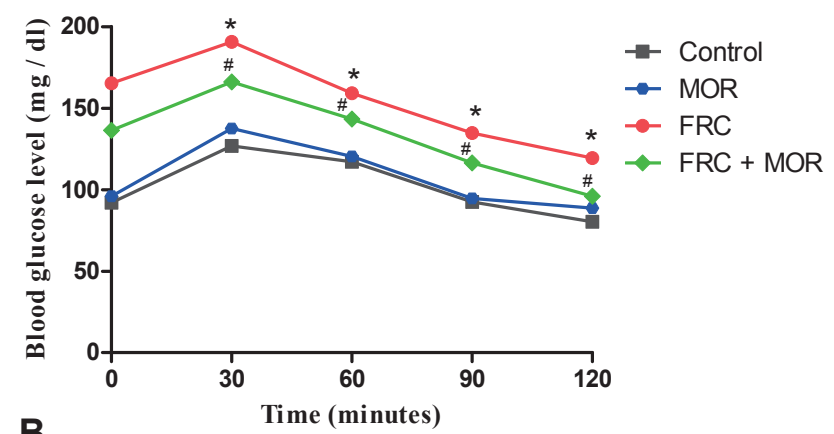

\section{B}

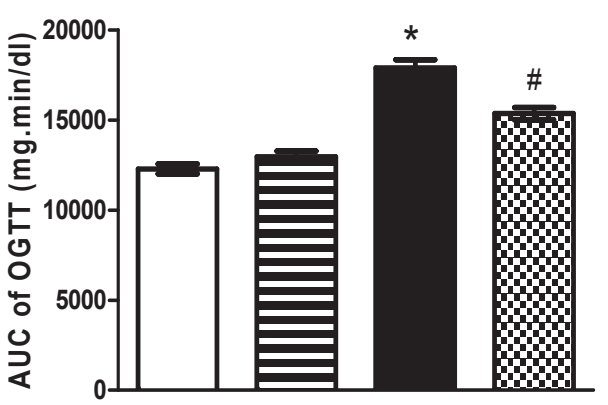

$\square$ Control
MOR
FRC
E FRC + MOR

Fig. 1. Effect of morin on OGTT (A) and AUC of OGTT (B) in fructosefed rats. Values are presented as mean \pm SEM ( $n=8$ rats). OGTT, oral glucose tolerance test; AUC, area under the curve; FRC, fructose; MOR, morin; MBS, metabolic syndrome. * * Significantly different from normal control and MBS groups, respectively at $\mathrm{p}<0.05$.

\section{Effect of morin on hepatic expressions of metabolic, inflammatory and fibrotic markers}

Hepatic expression of some inflammatory and fibrotic markers was performed in different groups and Western blotting methods. In Fig. 3, RT-PCR showed that the fructose diet for 12 weeks were down-regulated significantly $(\mathrm{p}<0.05)$ both NF- $\mathrm{KB}$ and GLUT2 mRNA expression levels. One the other hand, Fig. 4 produced a significant $(\mathrm{p}<0.05)$ up-regulating in protein expression levels of TNF- $\alpha$ and TGF- $\beta$ after induction of MBS as compared to the control group. In contrast, oral administration of morin significantly $(\mathrm{p}<0.05)$ reversed the above mentioned altered expression levels as compared to the MBS group. Remarkably, these favorable effects of morin on pro-inflammatory cytokines are leading to relieve the metabolic disorder complications.

\section{Effect of morin on hepatic histopathology}

The light microscopic examination of liver sections of the normal control (Fig. 5A) and control morin (Fig. 5B) groups elicited normal histological structure of the central vein (cv) and hepatocytes (h) as shown in Fig. 5 and Table 4. Hepatic sections of the fructose diet group (Fig. 5, C1) showed remarkable fatty changes (f) diffusely all over the hepatocytes in association with infiltration of inflammatory cells and a few fibrosis in the portal area (pa). Controversy, liver tissue of fructose-fed rats after morin treatment (Fig. 5, D1) exhibited a low inflammatory cells infiltration in the portal area incorporated with mild fatty changes in some hepatocytes (Fig. 5 and Table 4).

\section{DISCUSSION}

Prolonged consumption of fructose-rich diet is hazardous for human beings, as well as animals [20,28]. In the present study, fructose diet has been used for the induction of MBS which is a fundamental reason for the development of numerous chronic diseases. For example; hypertension, hepatic disorders and type 2 diabetes mellitus $[2,3]$. Flavonoids are phytochemical substances existing in morin that possess potent therapeutic effects in exper-

Table 3. Effect of morin on hepatic MDA, NO and reduced GSH levels, as well as CAT activity in fructose-induced metabolic syndrome in rats

\begin{tabular}{lcccc}
\hline Groups & $\begin{array}{c}\text { MDA } \\
\text { (nmol/g tissue) }\end{array}$ & $\begin{array}{c}\text { NO } \\
\text { (nmol/g tissue) }\end{array}$ & $\begin{array}{c}\text { GSH } \\
\text { (mmol/g tissue) }\end{array}$ & $\begin{array}{c}\text { Catalase } \\
(\text { U/g tissue })\end{array}$ \\
\hline Control & $177 \pm 8.6$ & $221 \pm 13.5$ & $31 \pm 1.7$ & $460 \pm 16.6$ \\
MOR & $178 \pm 9.5$ & $215 \pm 18.7$ & $32 \pm 2.1$ & $428 \pm 36.2$ \\
MBS & $392 \pm 17.3^{\mathrm{a}}$ & $381 \pm 25.3^{\mathrm{a}}$ & $16 \pm 1.8^{\mathrm{a}}$ & $257 \pm 22.4^{\mathrm{a}}$ \\
MBS + MOR & $279 \pm 10.9^{\mathrm{a}, \mathrm{b}}$ & $273 \pm 14.8^{\mathrm{a}, \mathrm{b}}$ & $33 \pm 1.1^{\mathrm{b}}$ & $463 \pm 31.8^{\mathrm{b}}$ \\
\hline
\end{tabular}

Data are represented as mean \pm SEM $(n=8$ rats). MDA, malondialdehyde; NO, nitric oxide; GSH, glutathione; CAT, catalase; MBS, metabolic syndrome; MOR, morin. ${ }^{a, b}$ Significantly different from normal control and MBS groups, respectively at $p<0.05$. 
imental models [29]. Interestingly, the medical benefits of flavonoids are most probably related to their potential antioxidant and free radical scavenging activities observed in vivo and in vitro studies [30].

Oxidative stress has been revealed as a causative factor results from MBS and strongly linked to in the development of insulin resistance, hyperinsulinemia and the progression of fatal chronic diseases [31,32].

Therefore, we further investigated the protective and antioxidant roles of morin on the pathogenesis of MBS in vivo. There are many hypotheses that could explain the powerful effect of morin against oxidative stress [33,34]. Prior research stated that the notion of morin being an efficient curative radical scavenger was also intensified by our observation that it scavenges peroxyl

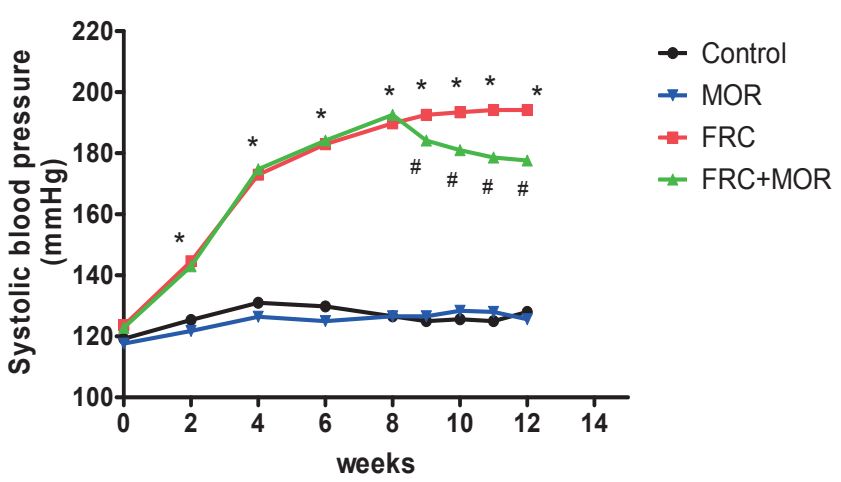

Fig. 2. Effect of morin on systolic blood pressure in MBS rats. Values are presented as mean \pm SEM ( $n=8$ rats). FRC, fructose; MOR, morin; MBS, metabolic syndrome. * "*Statistically significant from normal control and FRC groups, respectively at $p<0.05$ at each time point (week) by using two-way analysis of variance (ANOVA) followed by Bonferroni post analysis test. radicals better than other antioxidant for example vitamin $C$ and mannitol because of the hydroxyl group in position 2' of B ring, exclusively present in morin, seems to be related to its more effective antiradical activity. In previous studies, it also had been reported that the existence of morin boost the level of intracellular cAMP which in turn activate protein kinase A (PKA) in mammalian cells [35] that activation of the cAMP/PKA signaling pathway in endothelial cells plays an crucial role in the stimulation of autophagy [36].

The liver injury produces out flowing of liver enzymes to the blood stream as well as deposition of extracellular matrix [37]. Our data showed that the fructose diet promotes the occurrence of the hepatic steatosis, which is mainly manifested by the alteration in the body/muscle ratio, liver index, liver enzyme values and histopathological findings. However, with morin intervention, relieving in liver steatosis, this was confirmed through biochemical parameter and histopathology. It had been reported previously the morin as a natural supplement showed a hepatoprotective property against liver fibrosis induced by diethylnitrosamine in rats via suppressing Wnt/ $\beta$-catenin signaling [38].

Uchiyama and his colleagues [39] reported that oxidative stress stimulates a hepatic fat deposition because of presence ROS while, morin has a positive impact on metabolism-related parameters in MBS due to its stress eliminating properties. Previous study is in line with our finding, it confirmed that morin hydrate has a possible potential defensive mechanism against renal and hepatic tissue injury induced by cisplatin [40]. MBS had contributed to the increase in the serum level of blood glucose, insulin and SBP. It also elevated TC, TG and LDL-C serum levels, but reduced HDL-C serum level. While, in the morin group the imbalance serum levels of TG, TC, LDL-C, and HDL-C were approximately restored. The hypolipidemic effect of morin could be attributed to
A

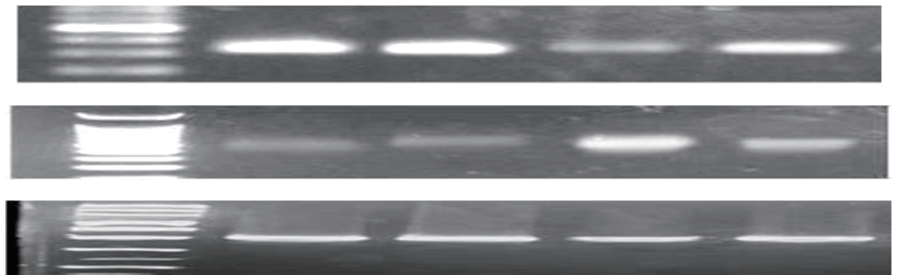

GLUT-2

NF-KB

\section{$\beta$-actin}

B

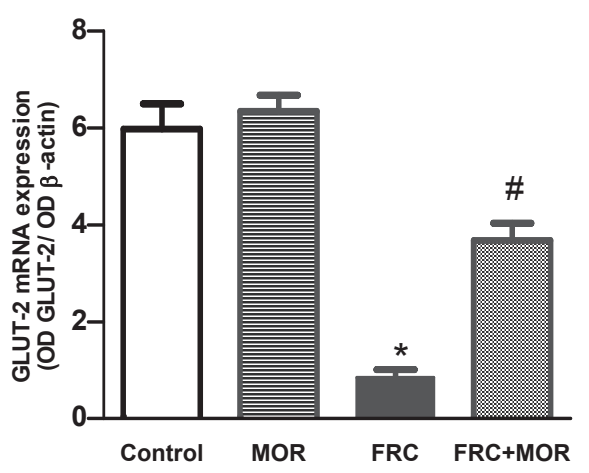

C

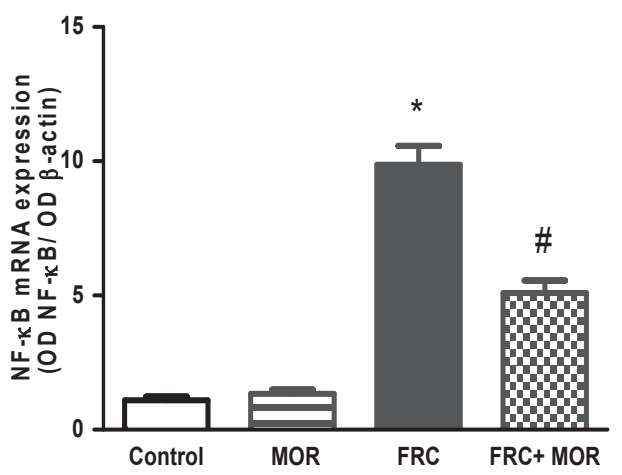

Fig. 3. Effect of morin on GLUT2 and NF-kB mRNA expressions in fructosefed rat's liver. Data are reported as: (A) representative electrophoretic analysis of RT-PCR products; (B) and (C) graphs present the ratio of densitometric measurements (optical density, OD) of samples to the corresponding reporter gene $(\beta$-actin). Values are presented as mean \pm SEM ( $n=8$ rats). GLUT2, glucose transporter 2; NF-KB, nuclear factor-kappa B; $F R C$, fructose; MOR, morin; MBS, metabolic syndrome. * * Statistically significant compared with normal control and MBS groups, respectively at $\mathrm{p}<0.05$. 
A
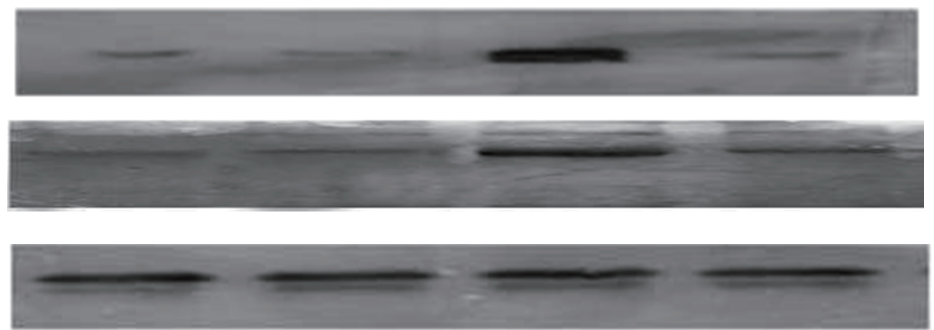

$\beta$-actin

B

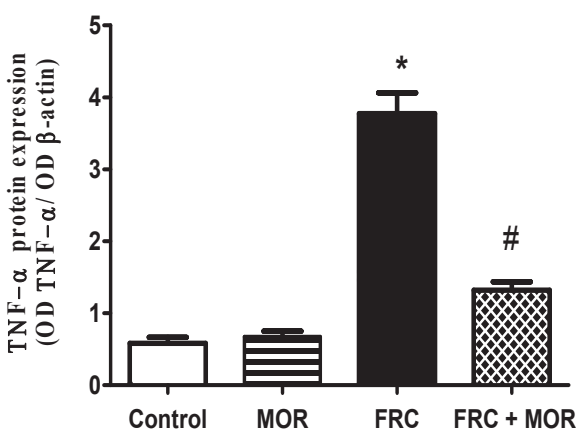

C

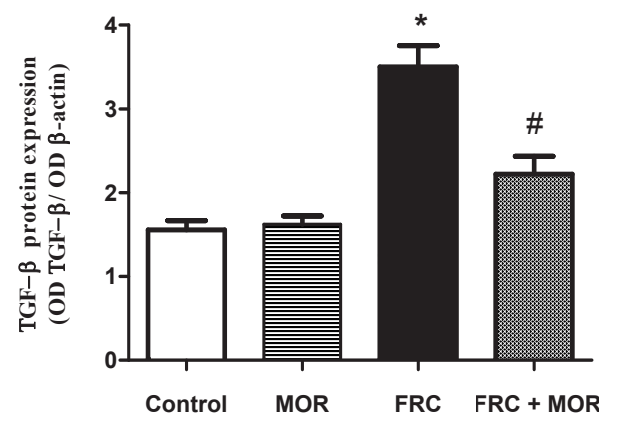

Fig. 4. Effect of morin on TNF- $\alpha$ and TGF- $\beta$ protein expressions in MBS rats. Data are reported as: (A) representative electrophoretic analysis of Western blotting products; $(\mathrm{B})$ and $(\mathrm{C})$ graphs present the ratio of densitometric measurements (optical density, OD) of samples to the corresponding reporter gene ( $\beta$-actin). Representative Western blots and the bar graph show analysis of four separate experiments ( $n=4$ rats). TNF- $\alpha$, tumor necrosis factor- $\alpha$; TGF- $\beta$, transforming growth factor- $\beta$; $F R C$, fructose; MOR, morin; MBS, metabolic syndrome. * "Statistically significant compared with normal control and MBS groups, respectively at $\mathrm{p}<0.05$. its strength to reduce cholesterol and TG levels alone or in combination with other antioxidants or hypolipidemic drugs [41].

Our data show that morin has a remarkable role in the improvement of insulin resistance and hyperinsulinemia. The effect of morin on the blood glucose level and insulin sensitivity is mediated through the regulation of carbohydrate metabolism enzyme activities which was previously proven by Abuohashish et al. [30] and Vanitha et al. [42]. Besides, another study determined the capability of morin to increase the phosphorylation of insulin receptor, inhibit gluconeogenesis and enhance glycogen synthesis which leads to improve glucose tolerance and insulin sensitivity [43]. Moreover, a prior study documented that morin was among five flavonoids that tested to eliminating glycated LDL-C level in a dose dependent manner in nitrite due to its antioxidant activity [44]. Morin also induced glycogen storage and down-regulated phosphoenol pyruvate carboxykinase and glucose-6-phosphatase protein expression [45]. Previous results demonstrated that morin limits ox-LDL-mediated injury by inducing autophagy via activating AMPK signalling in human umbilical vein endothelial cells [46].

Morin has advantageous effects on blood pressure by intensifying insulin sensitivity in the fructose-fed rats. Previous data indicated a strong connection between hyperinsulinemia and hypertension in the fructose diet induced MBS model $[2,47]$. Nevertheless, the mechanisms underlying fructose induced hypertension are not completely clarified. It had been proposed that the elevation of blood pressure due to the fructose diet in rats is secondary to the development of insulin resistance and hyperinsulinemia. That is compensatory hyperinsulinemia has been thought to be a cause of hypertension because insulin could cause sodium retention, activation of sympathetic nerve and proliferation of vascular smooth muscle cells $[47,48]$. In harmony with our data, prior reports suggested that morin acts as an antihypertensive and antioxidant agent against deoxycorticosterone acetate salt induced hypertension. The authors demonstrated that oral administration of morin entirely restores the kidney function due to its free radical scavenging activity $[49,50]$.

In the view of the results obtained, morin significantly attenuated oxidative stress and reversed both CAT and GSH activities close to their normal levels. It had been stated that the hydroxyl groups present at the C-3 and C-5, besides at C- 4 are indicated to be responsible for its antioxidant activity via quenching free radicals generated during oxidative stress conditions [30,51]. Morin restores redox hemostasis via sustaining superoxide neutralized property, boosting the activity of glutathione peroxidase and maintaining the concentration of GSH [49].

Our findings showed that morin supplementation eliminated lipid peroxidation which is in agreement with previous research results showed the ability of morin to prevent the adverse effect of oxidative damage $[41,50]$. In the present study, the inflammatory markers, NF- $\mathrm{B}$ and TNF- $\alpha$ were down-regulated however, GLUT2 was up-regulated after the treatment with morin. Recently, GLUT2 has drawn attentions as a transporter that could be included in the pathogenesis of diabetes mellitus because it is responsible for glucose transportation into the $\beta$-cells [52]. Earlier literature reported that flavonoids protect human hepatoma cell line functionality in high glucose concentration by reversing GLUT2 expression level and modulating glucose production and uptake $[53,54]$. The massive generation of ROS could certainly alternate gene expressions and activate several transcription factors such as $\mathrm{NF}-\kappa \mathrm{B}$ and then induces transcription of various proinflammatory genes [55]. The present study reveals that treatment with morin significantly reduced the expression of $\mathrm{NF}-\kappa \mathrm{B}$ and inhibited the inflammatory cascade by decreasing the hepatic 

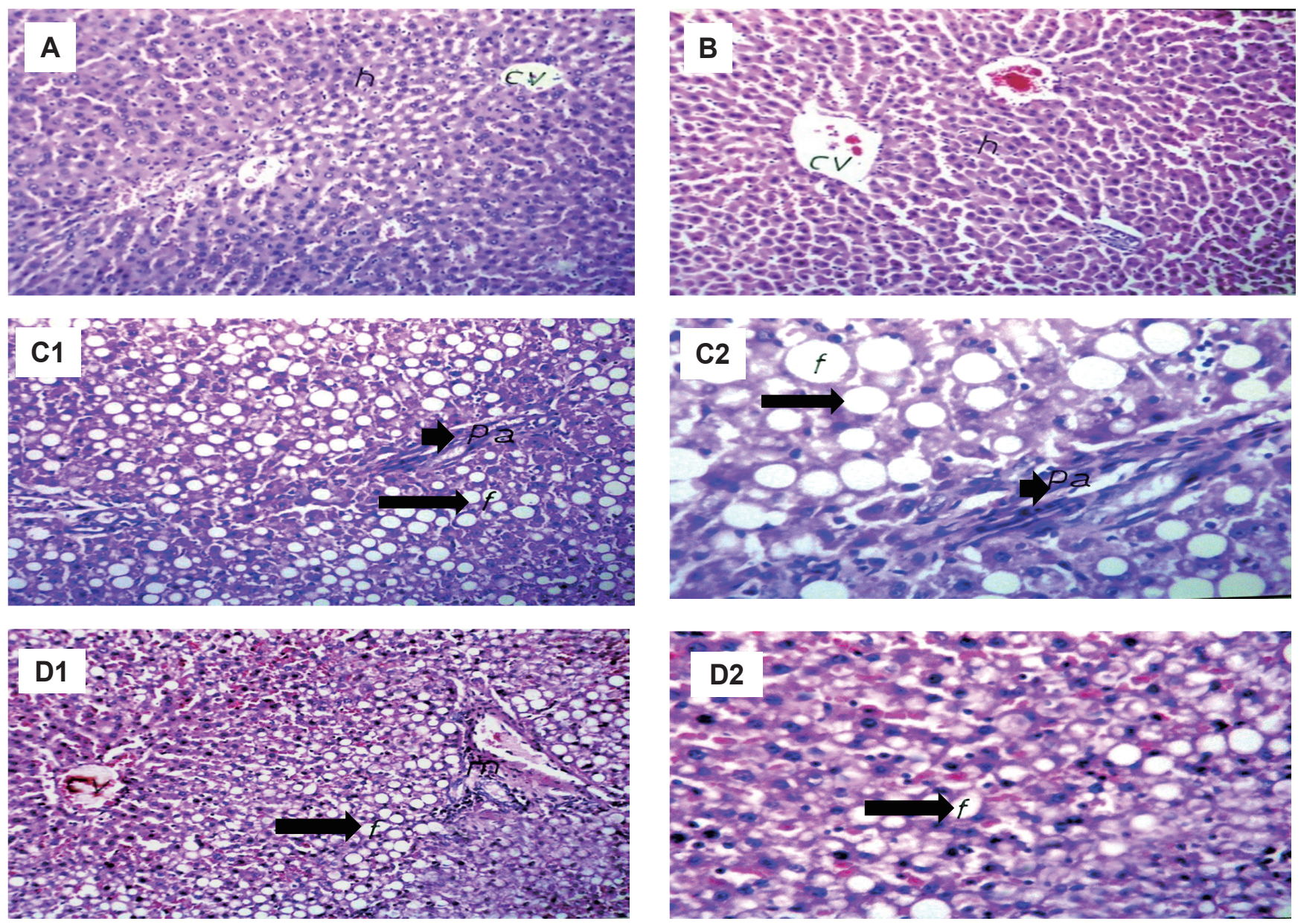

Fig. 5. Light microscopic examination of liver sections of normal control (A) and control morin (B) groups showing no histopathological alteration and normal histological structure of the central vein (cv) and surrounding hepatocytes (h) (H\&E x40). Hepatic section of MBS group (C1) shows fatty changes ( $f$ ) in a diffuse manner all over the hepatocytes (arrow) associated with inflammatory cells infiltration in between and few fibrosis in the portal area (pa) (arrow head) (H\&E x40); (C2) magnification of the same section at x80. Hepatic section of morin-treated group (D1) showing few inflammatory cells infiltration in the portal are associated with fatty change (arrow) in some of the hepatocytes and congestion in the central vein and sinusoids (H\&E x40); (D2) magnification of the same section at x80.

Table 4. Scoring of the histopathological changes associated with MBS feeding for 12 weeks and it's alteration by morin treatment

\begin{tabular}{lccccc}
\hline Groups & Steatosis & $\begin{array}{c}\text { Inflammatory } \\
\text { cells infiltration } \\
\text { in the portal area }\end{array}$ & $\begin{array}{c}\text { Inflammatory cells } \\
\text { infiltration in between } \\
\text { hepatocytes }\end{array}$ & $\begin{array}{c}\text { Congestion in } \\
\text { portal vein }\end{array}$ & $\begin{array}{c}\text { Fibrosis in } \\
\text { portal vein }\end{array}$ \\
Control & - & - & - & - & - \\
MOR & - & - & - & - & - \\
MBS & +++ & +++ & ++ & - \\
MBS + MOR & ++ & + & - & - \\
\hline
\end{tabular}

Score level - was considered no changes. Scores,+++ and +++ are mild, moderate and severe levels, revealing less than 25, 50, and $75 \%$ histopathological alterations of total fields examined, respectively. Score represents values obtained from tissue sections of 8 animals of each group, 5 fields/section. MBS, metabolic syndrome; MOR, morin.

expression of TNF- $\alpha$ and TGF- $\beta$. It has been reported that an improvement in one of gastrointestinal tract inflammatory disorders such as colitis in experimental animal treated with morin [30].
Previous studies showed that morin suppressed the production and expression of several inflammatory and fibrotic mediators including inducible nitric oxide synthase (iNOS), TNF- $\alpha$ and NF$\kappa B[18,56]$. In addition, it was confirmed that morin could effec- 
tively protect the liver from damage induced by carbon tetrachloride in rats by suppressing iNOS expressions and decreasing the production of inflammatory cytokines [57,58]. In agreement with our result, previous study showed that morin could be modulated oxidative stress-induced NF- $\mathrm{KB}$ pathway through the antioxidant defense mechanism and as satisfactory anti-inflammatory effect [59]. Furthermore, the protective role of morin in liver fibrosis presumably, at least in part, via reducing oxidative stress, inflammatory response, macrophage infiltration and consequently reduction of TGF- $\beta$ expression in the fructose diet induced MBS [56]. Also, it was recently reported that morin treatment inhibited liver fibrosis through stimulating apoptosis pathway, then lowering canonical NF- $\kappa \mathrm{B}$ signaling in the activated hepatic stellate cells [38].

In conclusion, the present study provides evidence of the potential protective effect of morin against chronic diseases such as hypertension, diabetes mellitus and hepatic disorders produced by MBS. These effects could be attributed to the ability of morin to up-regulate GLUT2 expression and ameliorate oxidative stress, inflammatory and fibrotic markers through down-regulation of NF- $\kappa$ B, TNF- $\alpha$, and TGF- $\beta$ expressions.

\section{CONFLICTS OF INTEREST}

The authors declare no conflicts of interest.

\section{REFERENCES}

1. Bray GA, Nielsen SJ, Popkin BM. Consumption of high-fructose corn syrup in beverages may play a role in the epidemic of obesity. Am J Clin Nutr. 2004;79:537-543.

2. Sánchez-Lozada LG, Tapia E, Jiménez A, Bautista P, Cristóbal M, Nepomuceno T, Soto V, Avila-Casado C, Nakagawa T, Johnson RJ, Herrera-Acosta J, Franco M. Fructose-induced metabolic syndrome is associated with glomerular hypertension and renal microvascular damage in rats. Am J Physiol Renal Physiol. 2007;292:F423-F429.

3. Kelishadi R, Mansourian M, Heidari-Beni M. Association of fructose consumption and components of metabolic syndrome in human studies: a systematic review and meta-analysis. Nutrition. 2014;30:503-510.

4. Sabir AA, Bilbis LS, Saidu Y, Jimoh A, Iwuala SO, Isezuo SA, Kaoje AU, Abubakar SA. Oxidative stress among subjects with metabolic syndrome in Sokoto, North-Western Nigeria. Niger J Clin Pract. 2016;19:128-132.

5. Lorenzo C, Okoloise M, Williams K, Stern MP, Haffner SM. The metabolic syndrome as predictor of type 2 diabetes: the San Antonio heart study. Diabetes Care. 2003;26:3153-3159.

6. Maki KC. Dietary factors in the prevention of diabetes mellitus and coronary artery disease associated with the metabolic syndrome. Am J Cardiol. 2004;93(11A):12C-17C.

7. Sivaramakrishnan V, Devaraj SN. Morin fosters apoptosis in experimental hepatocellular carcinogenesis model. Chem Biol Interact.
2010;183:284-292.

8. Zhang R, Kang KA, Kang SS, Park JW, Hyun JW. Morin (2',3, 4',5,7-pentahydroxyflavone) protected cells against $\gamma$-radiationinduced oxidative stress. Basic Clin Pharmacol Toxicol. 2011;108:6372.

9. Al Numair KS, Chandramohan G, Alsaif MA, Baskar AA. Protective effect of morin on cardiac mitochondrial function during isoproterenol-induced myocardial infarction in male Wistar rats. Redox Rep. 2012;17:14-21.

10. Yan X, Qi M, Li P, Zhan Y, Shao H. Apigenin in cancer therapy: anti-cancer effects and mechanisms of action. Cell Biosci. 2017;7:50.

11. Marunaka Y, Marunaka R, Sun H, Yamamoto T, Kanamura N, Inui T, Taruno A. Actions of quercetin, a polyphenol, on blood pressure. Molecules. 2017;22:209.

12. Choudhury A, Chakraborty I, Banerjee TS, Vana DR, Adapa D. Efficacy of morin as a potential therapeutic phytocomponent: insights into the mechanism of action. Int J Med Res Health Sci. 2017;6:175194.

13. Lotito SB, Frei B. Consumption of flavonoid-rich foods and increased plasma antioxidant capacity in humans: cause, consequence, or epiphenomenon? Free Radic Biol Med. 2006;41:1727-1746.

14. Cho YM, Onodera H, Ueda M, Imai T, Hirose M. A 13-week subchronic toxicity study of dietary administered morin in F344 rats. Food Chem Toxicol. 2006;44:891-897.

15. Caselli A, Cirri P, Santi A, Paoli P. Morin: a promising natural drug. Curr Med Chem. 2016;23:774-791.

16. Al-Numair KS, Chandramohan G, Alsaif MA, Veeramani C, El Newehy AS. Morin, a flavonoid, on lipid peroxidation and antioxidant status in experimental myocardial ischemic rats. Afr J Tradit Complement Altern Med. 2014;11:14-20.

17. Rehman MU, Rashid SM, Rasool S, Shakeel S, Ahmad B, Ahmad SB, Madkhali H, Ganaie MA, Majid S, Bhat SA. Zingerone (4-(4-hydroxy-3-methylphenyl)butan-2-one) ameliorates renal function via controlling oxidative burst and inflammation in experimental diabetic nephropathy. Arch Physiol Biochem. 2019;125:201-209.

18. Heeba GH, Mahmoud ME. Therapeutic potential of morin against liver fibrosis in rats: modulation of oxidative stress, cytokine production and nuclear factor kappa B. Environ Toxicol Pharmacol. 2014;37:662-671.

19. Tveden-Nyborg P, Bergmann TK, Lykkesfeldt J. Basic \& Clinical Pharmacology \& Toxicology policy for experimental and clinical studies. Basic Clin Pharmacol Toxicol. 2018;123:233-235.

20. Botezelli JD, Cambri LT, Ghezzi AC, Dalia RA, Voltarelli FA, de Mello MA. Fructose-rich diet leads to reduced aerobic capacity and to liver injury in rats. Lipids Health Dis. 2012;11:78.

21. Ola MS, Aleisa AM, Al-Rejaie SS, Abuohashish HM, Parmar MY, Alhomida AS, Ahmed MM. Flavonoid, morin inhibits oxidative stress, inflammation and enhances neurotrophic support in the brain of streptozotocin-induced diabetic rats. Neurol Sci. 2014;35:1003-1008.

22. Naderali EK, Williams G. Prolonged endothelial-dependent and -independent arterial dysfunction induced in the rat by shortterm feeding with a high-fat, high-sucrose diet. Atherosclerosis. 2003;166:253-259.

23. Matthews DR, Hosker JP, Rudenski AS, Naylor BA, Treacher DF, Turner RC. Homeostasis model assessment: insulin resistance and beta-cell function from fasting plasma glucose and insulin concen- 
trations in man. Diabetologia. 1985;28:412-419.

24. Friedewald WT, Levy RI, Fredrickson DS. Estimation of the concentration of low-density lipoprotein cholesterol in plasma, without use of the preparative ultracentrifuge. Clin Chem. 1972;18:499-502.

25. Ohkawa H, Ohishi N, Yagi K. Assay for lipid peroxides in animal tissues by thiobarbituric acid reaction. Anal Biochem. 1979;95:351358

26. Sastry KV, Moudgal RP, Mohan J, Tyagi JS, Rao GS. Spectrophotometric determination of serum nitrite and nitrate by coppercadmium alloy. Anal Biochem. 2002;306:79-82.

27. Beutler E, Duron O, Kelly BM. Improved method for the determination of blood glutathione. J Lab Clin Med. 1963;61:882-888.

28. Johnson RJ, Segal MS, Sautin Y, Nakagawa T, Feig DI, Kang DH, Gersch MS, Benner S, Sánchez-Lozada LG. Potential role of sugar (fructose) in the epidemic of hypertension, obesity and the metabolic syndrome, diabetes, kidney disease, and cardiovascular disease. Am J Clin Nutr. 2007;86:899-906.

29. Ma Y, Ge A, Zhu W, Liu YN, Ji NF, Zha WJ, Zhang JX, Zeng XN, Huang M. Morin attenuates ovalbumin-induced airway inflammation by modulating oxidative stress-responsive MAPK signaling. Oxid Med Cell Longev. 2016;2016:5843672.

30. Abuohashish HM, Al-Rejaie SS, Al-Hosaini KA, Parmar MY, Ahmed MM. Alleviating effects of morin against experimentallyinduced diabetic osteopenia. Diabetol Metab Syndr. 2013;5:5.

31. Carrier A. Metabolic syndrome and oxidative stress: a complex relationship. Antioxid Redox Signal. 2017;26:429-431.

32. McCracken E, Monaghan M, Sreenivasan S. Pathophysiology of the metabolic syndrome. Clin Dermatol. 2018;36:14-20.

33. Wu TW, Zeng LH, Wu J, Fung KP. Morin hydrate is a plant-derived and antioxidant-based hepatoprotector. Life Sci. 1993;53:PL213PL218.

34. Morales J, Günther G, Zanocco AL, Lemp E. Singlet oxygen reactions with flavonoids. A theoretical-experimental study. PLoS One. 2012;7:e40548.

35. Degenhardt K, Mathew R, Beaudoin B, Bray K, Anderson D, Chen G, Mukherjee C, Shi Y, Gélinas C, Fan Y, Nelson DA, Jin S, White E. Autophagy promotes tumor cell survival and restricts necrosis, inflammation, and tumorigenesis. Cancer Cell. 2006;10:51-64.

36. Liang C, E X, Jung JU. Downregulation of autophagy by herpesvirus Bcl-2 homologs. Autophagy. 2008;4:268-272.

37. Lim J, Ali ZM, Sanders RA, Snyder AC, Eells JT, Henshel DS, Watkins JB 3rd. Effects of low-level light therapy on hepatic antioxidant defense in acute and chronic diabetic rats. J Biochem Mol Toxicol. 2009;23:1-8.

38. MadanKumar P, NaveenKumar P, Devaraj H, NiranjaliDevaraj S. Morin, a dietary flavonoid, exhibits anti-fibrotic effect and induces apoptosis of activated hepatic stellate cells by suppressing canonical NF-КB signaling. Biochimie. 2015;110:107-118.

39. Uchiyama S, Shimizu T, Shirasawa T. CuZn-SOD deficiency causes ApoB degradation and induces hepatic lipid accumulation by impaired lipoprotein secretion in mice. J Biol Chem. 2006;281:3171331719.

40. K V A, Madhana RM, Kasala ER, Samudrala PK, Lahkar M, Gogoi R. Morin hydrate mitigates cisplatin-induced renal and hepatic injury by impeding oxidative/nitrosative stress and inflammation in mice. J Biochem Mol Toxicol. 2016;30:571-579.

41. Kang DG, Moon MK, Sohn EJ, Lee DH, Lee HS. Effects of morin on blood pressure and metabolic changes in fructose-induced hypertensive rats. Biol Pharm Bull. 2004;27:1779-1783.

42. Vanitha P, Uma C, Suganya N, Bhakkiyalakshmi E, Suriyanarayanan S, Gunasekaran P, Sivasubramanian S, Ramkumar KM. Modulatory effects of morin on hyperglycemia by attenuating the hepatic key enzymes of carbohydrate metabolism and $\beta$-cell function in streptozotocin-induced diabetic rats. Environ Toxicol Pharmacol. 2014;37:326-335.

43. Paoli P, Cirri P, Caselli A, Ranaldi F, Bruschi G, Santi A, Camici G. The insulin-mimetic effect of Morin: a promising molecule in diabetes treatment. Biochim Biophys Acta. 2013;1830:3102-3111.

44. Ghaffari MA, Mojab S. Influence of flavonols as in vitro on low density lipoprotein glycation. Iran Biomed J. 2007;11:185-191.

45. Naowaboot J, Wannasiri S, Pannangpetch P. Morin attenuates hepatic insulin resistance in high-fat-diet-induced obese mice. $J$ Physiol Biochem. 2016;72:269-280.

46. Zhang X, Han X, Zhang P, Zhou T, Chen Y, Jin J, Ma X. Morin attenuates oxidized low-density lipoprotein-mediated injury by inducing autophagy via activating AMPK signalling in HUVECs. Clin Exp Pharmacol Physiol. 2019;46:1053-1060.

47. Khitan Z, Kim DH. Fructose: a key factor in the development of metabolic syndrome and hypertension. J Nutr Metab. 2013;2013: 682673.

48. Masai M, Fujioka Y, Fujiwara M, Morimoto S, Miyoshi A, Suzuki $\mathrm{H}$, Iwasaki T. Activation of $\mathrm{Na}+\mathrm{H}+$ exchanger is associated with hyperinsulinemia in borderline hypertensive rats. Eur J Clin Invest. 2001;31:193-200.

49. Prahalathan P, Kumar S, Raja B. Morin attenuates blood pressure and oxidative stress in deoxycorticosterone acetate-salt hypertensive rats: a biochemical and histopathological evaluation. Metabolism. 2012;61:1087-1099.

50. Prahalathan P, Saravanakumar M, Raja B. The flavonoid morin restores blood pressure and lipid metabolism in DOCA-salt hypertensive rats. Redox Rep. 2012;17:167-175.

51. Merwid-Ląd A, Trocha M, Chlebda-Sieragowska E, Sozański T, Szandruk M, Magdalan J, Ksiądzyna D, Pieśniewska M, FereniecGołębiewska L, Kwiatkowska J, Szeląg A. The impact of morin, a natural flavonoid, on cyclophosphamide-induced changes in the oxidative stress parameters in rat livers. Adv Clin Exp Med. 2014; 23:505-509.

52. Hajiaghaalipour F, Khalilpourfarshbafi M, Arya A. Modulation of glucose transporter protein by dietary flavonoids in type 2 diabetes mellitus. Int J Biol Sci. 2015;11:508-524.

53. Cordero-Herrera I, Martín MA, Bravo L, Goya L, Ramos S. Cocoa flavonoids improve insulin signalling and modulate glucose production via AKT and AMPK in HepG2 cells. Mol Nutr Food Res. 2013;57:974-985.

54. Cordero-Herrera I, Martín MÁ, Goya L, Ramos S. Cocoa flavonoids attenuate high glucose-induced insulin signalling blockade and modulate glucose uptake and production in human HepG2 cells. Food Chem Toxicol. 2014;64:10-19.

55. Arab HH, Al-Shorbagy MY, Abdallah DM, Nassar NN. Telmisartan attenuates colon inflammation, oxidative perturbations and apoptosis in a rat model of experimental inflammatory bowel disease. PLoS One. 2014;9:e97193.

56. Lee HS, Jung KH, Park IS, Kwon SW, Lee DH, Hong SS. Protective effect of morin on dimethylnitrosamine-induced hepatic fibrosis in 
rats. Dig Dis Sci. 2009;54:782-788.

57. Lee HS, Jung KH, Hong SW, Park IS, Lee C, Han HK, Lee DH, Hong SS. Morin protects acute liver damage by carbon tetrachloride (CCl(4)) in rat. Arch Pharm Res. 2008;31:1160-1165.

58. Kim JM, Lee EK, Park G, Kim MK, Yokozawa T, Yu BP, Chung HY. Morin modulates the oxidative stress-induced NF-kappaB pathway through its anti-oxidant activity. Free Radic Res. 2010;44:454-461.

59. Gupta SC, Tyagi AK, Deshmukh-Taskar P, Hinojosa M, Prasad S, Aggarwal BB. Downregulation of tumor necrosis factor and other proinflammatory biomarkers by polyphenols. Arch Biochem Biophys. 2014;559:91-99. 